\title{
Studi Perencanaan Mitigasi Bencana Tsunami di Daerah Wisata Pantai Tablolong
}

\author{
Priska Gardeni Nahak, Djunaedi dan Tedi Wonlele
}

Jurusan Teknik Sipil, Politeknik Negeri Kupang, Jl. Adisucipto Penfui Kupang

Email: prigardeni2@gmail.com, selewah@gmail.com,tedy_wl@yahoo.com

\begin{abstract}
ABSTRAK
Pantai Tablolong merupakan salah pantai tujuan wisata yang terletak di Kecamatan Kupang Barat, Kabupaten Kupang. Letak Pantai Tablolong adalah di bagian ujung Barat dari Pulau Timor sehingga sangat rentan terhadap bahaya Tsunami. Penelitian ini menggunakan metode deskripsi dengan melakukan observasi dan kajian secara langsung di lapangan terhadap berbagai kondisi guna mengetahui seberapa besar dampak dan kerusakan yang mungkin terjadi. Penelitian ini bertujuan untuk: a) Menghitung waktu yang diperlukan oleh gelombang tsunami dari pusat patahannya ke Pantai Tablolong. b) Memperkirakan lokasi atau jarak penempatan alat detector peringatan dini. c) Mengkaji situasi yang ada di lapangan terhadap dampak yang akan ditimbulkan oleh gelombang tsunami. Berdasarkan hasil penelitian diketahui bahwa: waktu datang gelombang tsunami adalah 13,45 menit setelah terjadi dislokasi.; Lokasi pemasangan alat detector peringatan dini, yaitu pada jarak $31,6 \mathrm{~km}$ dari garis pantai, sehingga memberikan waktu sekitar 12 menit bagi wisatawan untuk menyelamatkan diri.; Tinggi gelombang pada saat mencapai pantai adalah $18 \mathrm{~m}$, sehingga tinggi run up gelombangnya adalah $40,7 \mathrm{~m}$.; Daerah yang terkena gelombang tsunami secara langsung adalah daerah di pantai selatan pulau Timor dan pulau Semau yang memiliki elevasi di bawah 40,7 m.; Pantai wisata Tablolong hanya akan terkena dampak tsunami berupa refleksi dari gelombang tsunami terhadap pulau Semau.
\end{abstract}

\section{Kata Kunci}

Pantai Tablolong, Tsunami, detector peringatan dini.

\section{PENDAHULUAN}

Gempa bumi dan gelombang tsunami tanggal 26 Desember 2005 silam telah mengakibatkan kehancuran dan penderitaan yang luar biasa bagi masyarakat, terutama di Propinsi Nanggroe Aceh Darussalam Nias dan Sumatera Utara. Tidak kurang dari 120.000 orang tewas dalam bencana tersebut dan lebih dari 400.000 orang kehilangan tempat tinggal dan harta benda mereka. Sementara infrastruktur dasar (suplay air bersih dan sanitasi, jalan dan jembatan, rumah sakit dan sekolah), telekomunikasi dan aliran listrik rusak parah.

Pulau Timor dalam SNI-1726-2002 [1]. Tentang Bangunan Tahan Gempa, dimasukkan dalam wilayah gempa 5 (urutan terbesar ke dua) yang berarti Pulau Timor merupakan daerah yang sangat rawan terhadap gempa bumi (gempa tektonik). Hal ini disebabkan karena pada bagian Selatan dari
Pulau Timor yaitu di Samudra Hindia merupakan lokasi pertemuan antar Lempeng Australia dan Lempeng Eurasia [2].

Akibatnya jika suatu saat terjadi patahan pada lokasi pertemuan tersebut, maka selain gempa bumi, juga akan mungkin terjadi Tsunami karena lokasi patahan berada di dalam Laut. Daerah terparah yang akan terkena dampak tsunami, adalah seluruh pantai selatan dari Pulau Timor.

Pantai Tablolong merupakan salah pantai tujuan wisata yang terletak di kecamatan Kupang Barat, Kabupaten Kupang. Letaknya $\pm 30 \mathrm{Km}$ dari Kota Kupang. Pantai ini terkenal karena pemandangan pantainya yang sangat indah. Selain itu air laut di pantai ini juga sangat jernih dan merupakan jalur migrasi ikan sehingga sangat kaya dengan berbagai jenis ikan seperti ikan Marlin dan jenis ikan lainnya sehingga selalu menjadi lokasi perlombaan 
memancing baik tingkat daerah dan tingkat internasional.

Letak Pantai Tablolong adalah di bagian ujung Barat dari Pulau Timor, walaupun lokasi pantai ini sedikit terlindung oleh pulau Semau, namun dampak tsunami akan tetap berpengaruh terhadap Pantai Tablolong, karena letaknya yang sangat dekat dengan Laut Selatan (Samudra Hindia). Oleh sebab itu Pantai Tablolong juga sangat rentan terhadap bahaya Tsunami. Sehingga perlu adanya upaya penanggulangan sejak dini terhadap Pantai Tablolong sebagai daerah Pariwisata, sehingga wisatawan yang datang ke Pantai Tablolong tetap merasa aman dan nyaman.

Upaya penanggulangan yang dilakukan dapat melalui kajian-kajian dengan berbagai kondisi, guna mengetahui seberapa besar kerusakan yang mungkin terjadi, dengan beberapa variasi ketinggian gelombang tsunami, sehingga dapat ditentukan konsep mitigasi apa yang dapat diterapkan.

\section{TINJAUAN PUSTAKA}

Tsunami berasal dari kata Jepang "tsu" pelabuhan/laut dan "nami" berarti gelombang. US Army Corps of Engineers (1990) dalam Kodoatie dan Rustam Syarief (2006) [3] mendefinisikan tsunami sebagai gelombang laut gravitasi periode panjang yang ditimbulkan oleh gangguan seperti gerakan patahan, gempa, longsor, jatuhnya bendabenda langit (meteor), letusan gunung berapi dibawah laut dan letusan (exploison) di dekat muka air laut.

Gelombang tsunami merupakan gelombang panjang yang tidak dispersif, mengalami refraksi, defraksi dan shoaling.

\section{a. Tidak Dispersif}

Energi gelombang dibawa oleh gelombang dengan kecepatan sama dengan gelombangnya sehingga energi gelombang hampir tidak berkurang selama perjalanannya.

Persamaan-persamaan Energi:

1) Kotinuitas Fluks: Kontinuitas Fluks energi

$$
\begin{aligned}
& F 1=F 2 \\
& (\text { E.n.C.b })_{1}=(\text { E.n.C.b })_{2}
\end{aligned}
$$

2) Energi gelombang berjalan dengan kecepatan

$$
C=\sqrt{g h}
$$

$$
\begin{aligned}
& \text { dengan, } \\
& \qquad \begin{array}{l}
\mathrm{g}=\text { percepatan gravitasi bumi }=9,81 \\
\mathrm{~m} / \mathrm{dt}^{2}
\end{array} \\
& \mathrm{~h}=\text { kedalaman laut }(\mathrm{m})
\end{aligned}
$$

3) Besarnya energi gelombang sinus

$$
\begin{aligned}
& E=\frac{\rho g L H^{2}}{8} \\
& \text { dengan, } \\
& \rho=\text { berat massa air }=1 \\
& \mathrm{~L}=\text { panjang gelombang }(\mathrm{m}) \\
& \mathrm{H}=\text { kedalaman laut }(\mathrm{m}) \\
& \mathrm{g}=\text { percepatan gravitasi }=9,81 \mathrm{~m} / \mathrm{dt}^{2}
\end{aligned}
$$

\section{b. Refraksi}

Refraksi terjadi karena gelombang berbelok akibat berjalan pada kedalaman yang tidak rata, sehingga terjadi perubahan tinggi gelombang dan menyebabkan energi gelombang dapat menyebar atau berkumpul.

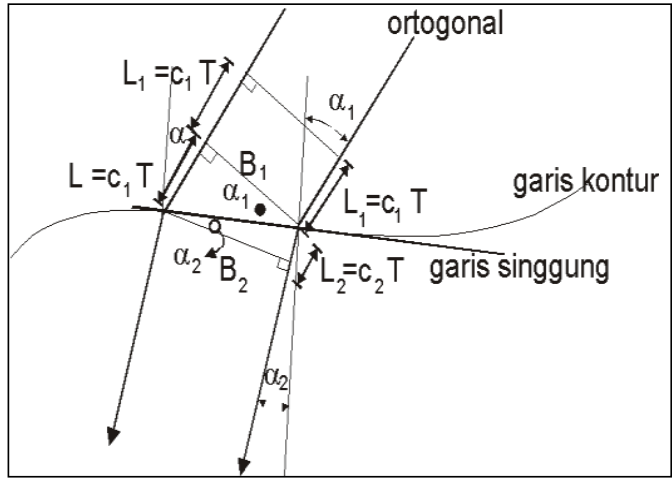

Gambar 1. Proses refraksi

c. Defraksi

Gelombang menyebar ke daerah yang lebih luas karena tertahan, hal ini menyebabkan daerah yang terlindung masih mungkin terkena serangan.

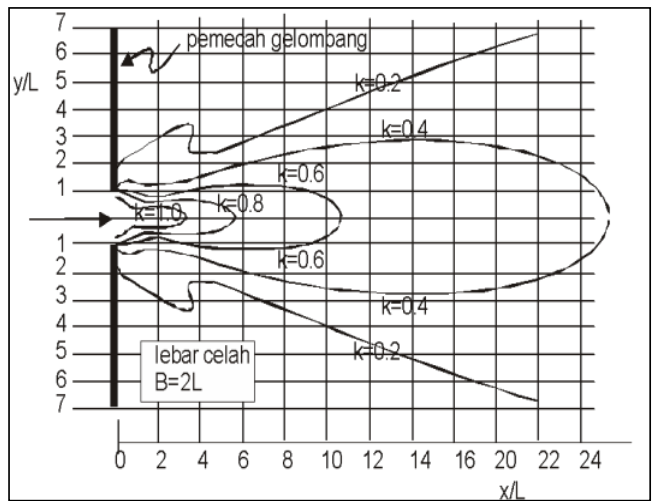

Gambar 2. Defraksi gelombang tsunami 


\section{d. Shoaling}

Jika energi gelombang tidak berkurang terhadap gesekan dengan dasar laut, maka pada kedalaman kecil kecepatan (C) juga kecil sehingga panjang gelombang (L) pun mengecil. Pada kedalaman kecil, gelombang lebih pendek, sehingga jika energi konstan gelombang harus lebih tinggi.

$$
\mathbf{L}=\mathbf{C T}
$$

Dengan;

$\mathrm{C}=$ kecepatan gelombang

$\mathrm{T}=$ perioda gelombang

Persamaan shoaling:

$$
H_{2}=\frac{\sqrt{b_{1}}}{\sqrt{b}} \frac{\sqrt{C_{1} n_{1}}}{\sqrt{C_{2} n_{2}}}
$$

Dengan:

$$
\begin{aligned}
& \mathrm{H}=\text { tinggi gelombang } \\
& \mathrm{b}=\text { lebar gelombang } \\
& \mathrm{C}=\text { kecepatan (jalar) gelombang } \\
& \mathrm{n}=1 \text { (untuk gelombang tsunami) }
\end{aligned}
$$

\section{e. Refleksi}

Gelombang tsunami dapat memantulkan energinya jika membentur sesuatu bidang yang keras sehingga dapat mengenai bidang di depannya.

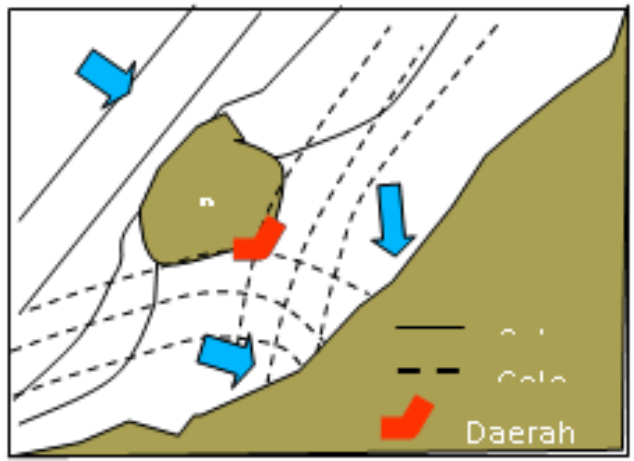

Gambar 3. Refleksi gelombang tsunami

\section{f. Run Up}

Gelombang tsunami dapat mengalami run up, sehingga daerah yang tinggi masih mungkin terkena tsunami. Untuk menghitung run up dari gelombang tsunami dapat dilakukan dengan melihat grafik hubungan antara $\mathrm{Ru} / \mathrm{H}$ atau $\mathrm{Rd} / \mathrm{H}$ terhadap angka irrabaren berikut ini:

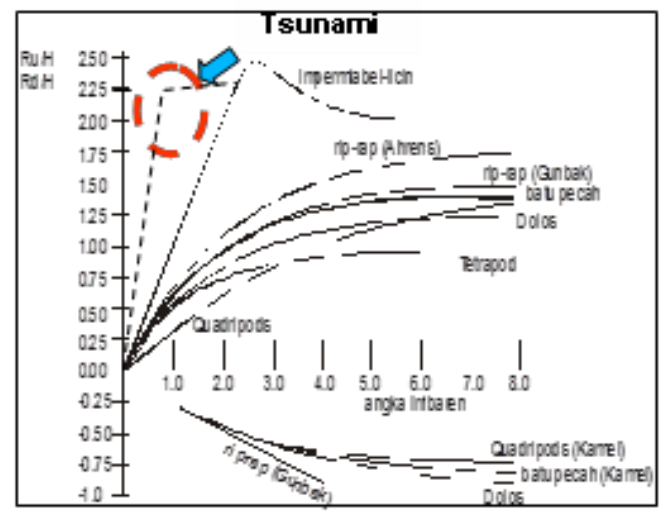

Gambar 4. Grafik Run up/ Run down

\section{METODE PENELITIAN}

\section{Tahapan Penelitian}

\section{a) Pengumpulan Data}

Data yang dikumpulkan berupa data Primer dan data Sekunder. Data Primer diperoleh melalui hasil survey dan kajian di lapangan berupa data situasi lapangan. Sedangkan data sekunder diperoleh dari instansi terkait, meliputi: data peta rupa bumi digital Indonesia, data titik-titik pusat gempa di sekitar Samudra Hindia

\section{b) Pengolahan Data}

a. Menghitung secara kuantitatif dari data/peta yang diberikan

1) Menentukan 2 titik pusat gempa yang paling berpengaruh yang pernah terjadi. Ke dua titik ini akan digunakan sebagai titik pusat patahan/sumber gelombang tsunami.

2) Untuk menghitung waktu tiba dari gelombang tsunami ke Pantai Tablolong dari dua lokasi lokasi patahan yang berbeda.

3) Untuk menghitung perkiraan lokasi/jarak penempatan detector dini yang dapat memberikan waktu tertentu bagi warga/wisatawan untuk menyelamatkan diri dari gelombang tsunami.

4) Menghitung kemungkinan run-up yang terjadi di Pantai Tablolong.

5) Melihat daerah mana saja yang akan terkena gelombang tsunami (dari perhitungan sebelumnya). 
b. Melakukan kajian kualitatif

Kajian kualitatif dilakukan dengan membaca situasi di lapangan, hasil survey ke Pantai Tablolong, kemudian memperkirakan lokasi dan rute evakuasi yang dianggap paling tepat, terdekat dan teraman bagi wisatawan dan warga sekitar, membuat Peta Kerawanan Bahaya Tsunami, dan melakukan penataan terhadap Pantai Tablolong agar ramah terhadap bahaya tsunami.

\section{HASIL DAN PEMBAHASAN}

\subsection{Lokasi Patahan di Laut}

Dari Data yang diperoleh dari Badan Meteorologi dan Geofisika, maka dipilih dua kemungkinan lokasi patahan yang berada di Laut Timor (selatan Pulau Timor) yang diperkirakan dapat memicu terjadinya tsunami di Pantai Tablolong. Kedua lokasi ini dipilih berdasarkan lokasi pusat gempa yang pernah terjadi di sekitar daerah patahan, tanpa memperhatikan kekuatan gempanya. Kedua lokasi yang dipilih dapat dilihat pada Gambar di bawah ini.

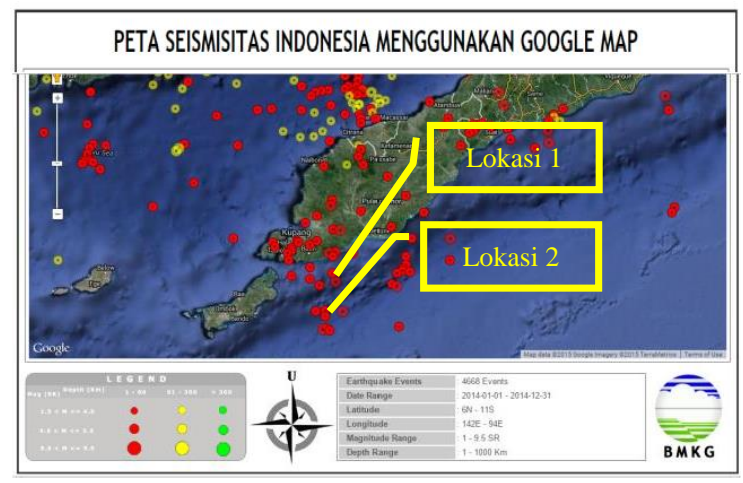

Gambar 5. Lokasi titik pusat gempa yang dipakai

\subsection{Waktu Datang Gelombang Tsunami}

Menghitung waktu yang dibutuhkan oleh gelombang tsunami dari lokasi patahan yang ditunjukkan dalam peta hingga ke Tablolong.

\section{a. Lokasi pertama}

- Jarak lokasi patahan 1 dengan Pantai Oisina (ujung pulau Timor) $=66,17 \mathrm{Km}$

- Jarak lokasi patahan 1 terhadap Pulau Semau $=74,43 \mathrm{Km}$
Pada peta elevasi terlihat bahwa kedalaman laut di luar garis cakupan pantai 12mil $(19,308 \mathrm{Km})$ hampir merata dengan kedalaman kurang lebih 4000m, sedangkan kedalaman laut di dalam garis cakupan pantai bervariasi dan dianggap berubah secara linear mulai dari $300 \mathrm{~m}$ hingga $2 \mathrm{~m}$.

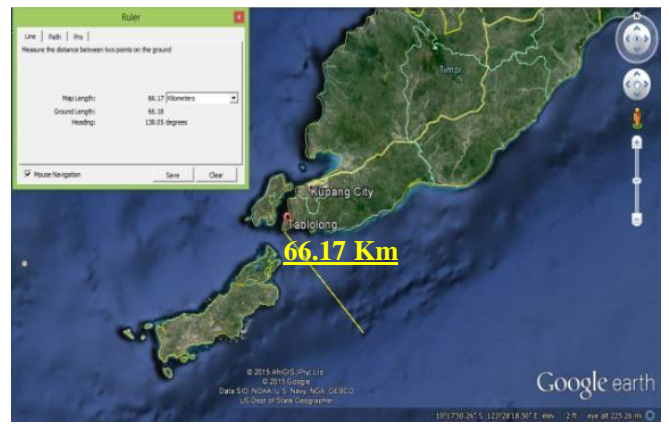

Gambar 6. Foto udara lokasi patahan satu terhadap pantai Oisina

- Total waktu yang dibutuhkan gelombang tsunami (dari lokasi patahan pertama) untuk sampai ke Pantai Tablolong adalah:

$\mathrm{t}_{1}+\mathrm{t}_{2}=3,94+10,97=\mathbf{1 4 , 9 1}$ menit.

Dengan cara yang sama dapat ditentukan waktu tempuh gelombang tsunami dari lokasi patahan 1 ke Pulau Semau $=t_{1}+t_{2}$ $=4,65+10,97=\mathbf{1 5 , 6 2}$ menit.

Jadi waktu yang dibutuhkan oleh gelombang tsunami dari lokasi 1 untuk sampai ke ujung pulau Timor (Pantai Oisina) dan Pulau Semau adalah 14,91 menit dan 15,62 menit

\section{b. Lokasi kedua}

- Jarak lokasi patahan 2 dengan pantai Oisina (ujung pulau Timor) $=48,95 \mathrm{Km}$

- Jarak lokasi patahan 2 dengan Pulau Semau $=55,25 \mathrm{Km}$

- Pada peta elevasi dapat terlihat bahwa kedalaman laut di luar garis cakupan pantai 12 mil $(19,308 \mathrm{Km})$ hampir merata dengan kedalaman kurang lebih 4000m, sedangkan kedalaman laut didalam garis cakupan pantai bervariasi dan dianggap berubah secara linear mulai dari 300m hingga $2 \mathrm{~m}$. 


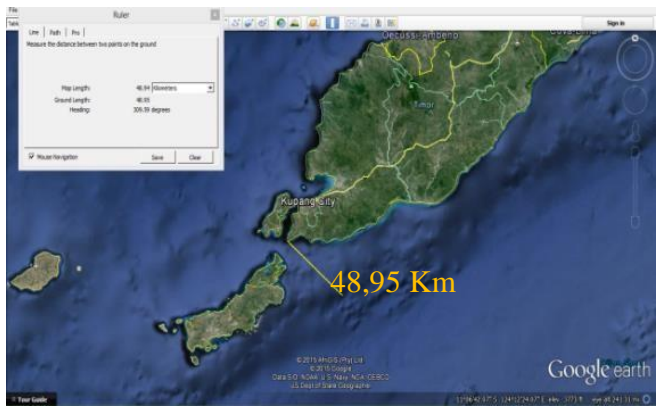

Gambar 7 . Foto udara lokasi patahan dua terhadap Pantai Oisina

a) Total waktu yang dibutuhkan gelombang tsunami (pada lokasi kedua) untuk sampai ke pantai Tablolong adalah $\mathrm{t}_{1}+\mathrm{t}_{2}=2,48+10,97=\mathbf{1 3 , 4 5}$ menit.

Dengan cara yang sama dapat ditentukan waktu tempuh gelombang tsunami dari lokasi patahan ke- 2 dengan Pulau Semau $=\mathrm{t}_{1}+\mathrm{t}_{2}=3,02+10,97=\mathbf{1 3 , 9 9}$ menit.

Jadi waktu yang dibutuhkan oleh gelombang tsunami dari lokasi 1 untuk sampai ke ujung pulau Timor (Pantai Oisina) dan Pulau Semau adalah $\mathbf{1 3 . 4 5}$ menit dan 13.99 menit

Tabel 1. Rekapan Waktu Datang Gelombang Tsunami

\begin{tabular}{|c|l|c|c|}
\hline No & \multicolumn{1}{|c|}{ Lokasi } & $\begin{array}{c}\text { Jarak } \\
\mathbf{( K m})\end{array}$ & $\begin{array}{c}\text { Waktu tempuh } \\
\text { gelombang } \\
\text { Tsunami (Menit) }\end{array}$ \\
\hline 1. & $\begin{array}{l}\text { Lokasi 1 dengan } \\
\text { pantai Oisina }\end{array}$ & 66,17 & 14,91 \\
\hline 2. & $\begin{array}{l}\text { Lokasi 1 dengan } \\
\text { pulau Semau }\end{array}$ & 74,43 & 15,62 \\
\hline 3. & $\begin{array}{l}\text { Lokasi 2 dengan } \\
\text { pantai Oisina }\end{array}$ & 48,95 & $\mathbf{1 3 , 4 5}$ \\
\hline 4. & $\begin{array}{l}\text { Lokasi 2 dengan } \\
\text { pulau Semau }\end{array}$ & 55,25 & 13,99 \\
\hline
\end{tabular}

Sumber: Hasil perhitungan

Berdasarkan tabel rekapan di atas, maka dapat ditentukan waktu datang gelombang tsunami ke pantai Oisina diambil nilai yang paling kritis, yaitu: 13,45 menit.

\subsection{Letak Penempatan Detektor}

Agar masyarakat menjadi waspada terhadap ancaman bahaya tsunami perlu dilakukan pemasangan suatu alat early warning system yang sederhana berupa detector peringatan dini.

Waktu deteksi = 12 menit (sebelum mencapai Pantai Oisina)
Pada perhitungan sebelumnya diketahui bahwa selama di dalam batas cakupan garis pantai $\left(S_{1}=19,308 \mathrm{~km}\right)$, maka waktu yang diperlukan gelombang tsunami mencapai pantai adalah 10,97 menit, sehingga tersisa waktu sebanyak $(12-10,97)=$ 1,03 menit, yaitu pada kedalaman laut yang dianggap sama (sekitar $4000 \mathrm{~m}$ ), sehingga jaraknya yang tersisa untuk waktu (1,03 menit) adalah :

- $\operatorname{Jarak}(\mathrm{S})=$ waktu $(\mathrm{t}) * \operatorname{kecepatan}(\mathrm{C})$

- Pada perhitungan sebelumnya diketahui kecepatan pada kedalaman 4000 m adalah 198,1 $\mathrm{m} / \mathrm{dt}$.

- Sehingga, Jarak $(S)=1,03 * 60 * 198,1$ $\mathrm{S}_{2}=12242,6 \mathrm{~m}$

Jadi jarak ideal diletakkannya detector peringatan dini agar gelombang tsunami dapat terdeteksi 12 menit sebelum mencapai pantai adalah :

$\mathrm{S}_{1}+\mathrm{S}_{2}=19.308 \mathrm{~m}+12.242,6 \mathrm{~m}=31.550,6 \mathrm{~m}$

atau $31,6 \mathrm{Km}$ dari garis pantai.

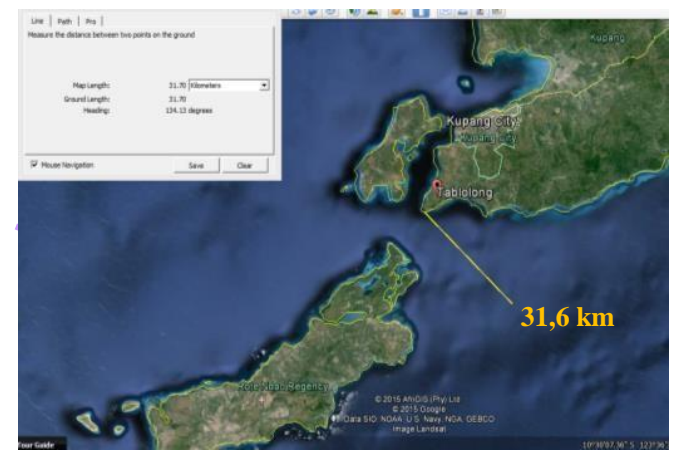

Gambar 8. Perkiraan penempatan detektor

\subsection{Tinggi Run Up Gelombang Tsunami}

Bila diasumsikan tinggi gelombang tsunami saat terjadi dislokasi adalah 5 meter dengan panjang gelombang tsunami sebesar $20 \mathrm{~km}$, maka kemungkinan tinggi run-up pada pantai Tablolong dapat dihitung dengan terlebih dahulu menghitung tinggi gelombang tsunami ketika sampai ke pantai dengan menggunakan persamaan shaoling dengan asumsi bahwa nilai b-nya konstant, sebagai berikut: 
Diketahui data asumsi:

$$
\begin{array}{ll}
\text { - } & \mathrm{H}_{1}=5 \mathrm{~m} \\
. & \mathrm{h}_{1}=4000 \mathrm{~m} \\
\text { - } & \mathrm{h}_{2}=2 \mathrm{~m} \\
& \mathrm{~L}=20 \mathrm{~km}
\end{array}
$$

Tinggi Gelombang dihitung dengan persamaan shoaling:

$$
\frac{\mathrm{H}_{2}}{\mathrm{H}_{1}}=\frac{\sqrt{\mathrm{b}_{1}}}{\sqrt{\mathrm{b}_{2}}} \frac{\sqrt{\mathrm{C}_{1}}}{\sqrt{\mathrm{C}_{2}}}=\frac{\sqrt{\mathrm{b}_{1}}}{\sqrt{\mathrm{b}_{2}}} \frac{\sqrt{\sqrt{\mathrm{gh}_{1}}}}{\sqrt{\sqrt{\mathrm{gh}_{2}}}}
$$

Tinggi gelombang harus memenuhi persamaan: $\frac{H}{d}=0.78$

Dari hasil perhitungan didapat tinggi gelombang $(\mathrm{H})=18,12 \mathrm{~m}$.

Dengan tinggi gelombang ketika mencapai pantai adalah $18 \mathrm{~m}$, maka tinggi run up dari gelombang tsunami ini dengan nilai $\mathrm{Ru} / \mathrm{H}$ sebesar 2,25 (Gambar 4) adalah

$\mathrm{Ru}=2,25 * \mathrm{H}_{2}$

$\mathrm{Ru}=2,25 * 18,12$

\section{$\underline{\mathrm{Ru}}=\mathbf{4 5}, \mathbf{3} \mathrm{m}$.}

\subsection{Daerah yang Berpotensi Terkena Dampak Tsunami}

Dengan tinggi run-up yang mencapai 45,3 m, dan panjang gelombang $20 \mathrm{~m}$ maka diperkirakan daerah yang akan terkena tsunami adalah:

a. Daerah yang terkena gelombang tsunami secara langsung adalah daerah-daerah yang langsung berhadapan dengan gelombang tsunami yaitu di sepanjang pantai selatan Pulau Rote, pantai-pantai di selatan Pulau Timor dan ujung selatan Pulau Semau, yang memiliki elevasi yang lebih rendah dari pada tinggi run- up gelombang tsunami tersebut $(45,3 \mathrm{~m})$.

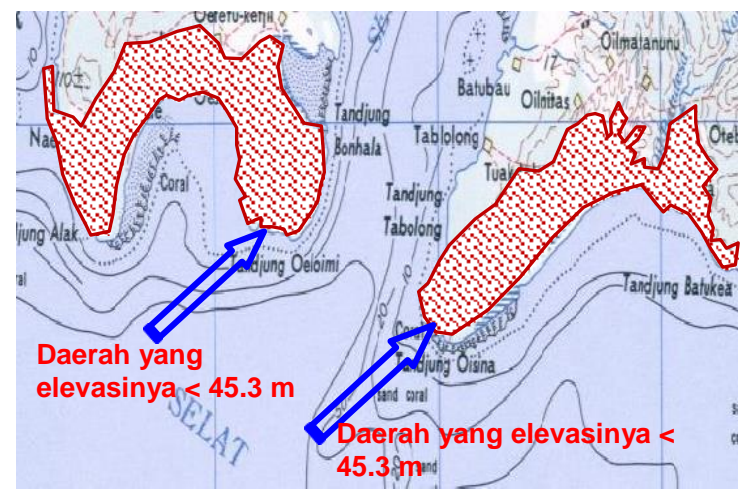

Gambar 9. Peta daerah yang berpotensi terkena gelombang tsunami secara langsung b. Pantai Tablolong berpotensi terkena gelombang tsunami secara langsung melalui Pantai Oisina, namun karena elevasi di Pantai Oisina lebih dari $45.3 \mathrm{~m}$, maka dengan sendirinya Pantai Tablolong juga tidak akan terkena hempasan gelombang tsunami secara langsung. Walau tidak terkena gelombang tsunami secara langsung, namun Pantai Tablolong sangat berpotensi terkena refleksi dari gelombang tsunami, karena posisinya yang berada persis di belakang dari Pantai Oisina dan di depan Pulau Semau. Jadi daerah yang terkena refleksi akibat gelombang tsunami dapat dilihat pada Gambar 10.

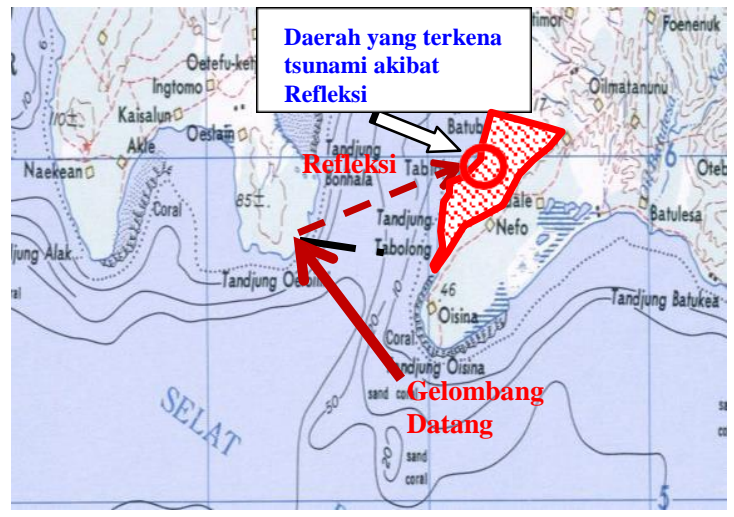

Gambar 10. Perkiraan lokasi yang mungkin terkena refleksi akibat gelombang Tsunami

\section{KESIMPULAN}

Berdasarkan hasil analisa, dan pembahasan di atas, maka dapat disimpulkan sebagai berikut:

1. Waktu datang gelombang tsunami adalah 13,45 menit setelah terjadi dislokasi. Nilai ini dihitung dari pusat lokasi terhadap ujung selatan Pulau Timor yang juga sangat dekat dengan lokasi wisata Pantai Tablolong, dan pulau Semau

2. Agar masyarakat menjadi waspada terhadap ancaman bahaya tsunami, maka perlu dilakukan pemasangan suatu alat early warning system yang sederhana berupa detektor peringatan dini pada jarak 31,6 km dari garis pantai, sehingga memberikan waktu sekitar 12 menit bagi wisatawan untuk menyelamatkan diri.

3. Tinggi gelombang pada saat mencapai pantai adalah $18 \mathrm{~m}$ (jika tinggi gelombang saat dislokasi $=5 \mathrm{~m}$ ), sehingga tinggi run up gelombang adalah $40,7 \mathrm{~m}$.

4. Daerah yang terkena gelombang tsunami secara langsung adalah daerah di pantai selatan Pulau Timor dan Pulau Semau yang memiliki elevasi di bawah $40,7 \mathrm{~m}$. 
5. Pantai wisata Tablolong tidak terkena gelombang tsunami secara langsung, namun tetap akan terkena dampak tsunami berupa refleksi gelombang tsunami terhadap Pulau Semau.

\section{UCAPAN TERIMA KASIH}

Terima kasih yang tulus kami sampaikan kepada Kementrian Riset Teknologi dan Pendidikan Tinggi

Republik Indonesia yang telah mendanai penelitian ini.

\section{DAFTAR PUSTAKA}

[1] SNI 03 - 1726-2003, Tata Cara Perencanaan Ketahanan untuk Bangunan Gedung, DPU

[2] http://id.wikipedia.org/wiki/Tectonic_plates.

[3] Kodoatie Robert dan Rustam sjarief, 2006, Pengelolaan Bencana Terpadu (Banjir, longsor, kekeringan dan tsunami), Yarsif Watampone, Jakarta

[4] Bambang Triatmodjo, 1999, Teknik

Pantai, Beta Offset, Yogyakarta

[5] Coburn A.W.,Spence R.J.S dan Pomonis A., 1994, Modul Mitigasi Bencana, UNDP

[6] Radianta Triatmadja, 2007, Bahan kuliah MagisterPengelolaan Bencana Alam, Universitas Gadjah Mada, Yogyakarta.

[7] Yayasan IDEP, 2005, Panduan Umum Penanggulangan Bencana berbasis Masyarakat, Denpasar (www.idepfoundation.org/pbbm) 